\title{
Efficacy of interventional therapy and effect on inflammatory factors in patients with gastric cancer after chemotherapy
}

\author{
PUZHAO $\mathrm{WU}^{1 *}$ and $\mathrm{JING}_{\mathrm{WANG}}{ }^{2 *}$ \\ Departments of ${ }^{1}$ Interventional Oncology and ${ }^{2}$ Oncology, Xiangyang No. 1 People's Hospital, Hubei University of Medicine, \\ Xiangyang, Hubei 441000, P.R. China
}

Received August 23, 2018; Accepted May 14, 2019

DOI: $10.3892 / \mathrm{ol} .2019 .10505$

\begin{abstract}
The clinical effect of interventional therapy on gastric cancer after chemotherapy and effect on inflammatory factors in peripheral blood serum of patients were investigated. A retrospective analysis of 429 patients with gastric cancer treated in Xiangyang No. 1 People's Hospital, Hubei University of Medicine from July 2008 to December 2014 was performed. Among them, 220 patients received interventional therapy after chemotherapy as the experimental group, and 209 patients received conventional therapy as the control group. Serum carcinoembryonic antigen (CEA), tumor markers CA19-9, interleukin-6 (IL-6), interleukin-8 (IL-8) and interleukin-10 (IL-10) levels were measured before and after chemotherapy. The correlation between the concentration of CEA and CA19-9 before and after treatment and the levels of IL-6, IL-8 and IL-10 were analyzed in the experimental group, and all patients were followed up for 3 years. There were no significant differences in CEA, CA19-9, IL-6, IL-8 and IL-10 between the two groups before chemotherapy $(\mathrm{P}>0.05)$. After treatment, the concentrations of CEA, CA19-9, IL-6, IL-8 and IL-10 in the experimental group were significantly lower than those in the control group before and after treatment $(\mathrm{P}<0.05)$. The clinical efficacy and adverse reactions of the experimental group were significantly better than those in the control group $(\mathrm{P}<0.05)$. Pearson's correlation analysis showed that the concentrations of CEA and CA19-9 in the serum of the experimental group before and after treatment were positively correlated with the levels of IL-6, IL-8 and IL-10 $(\mathrm{P}<0.05)$. The 3-year overall survival rate of the study group was significantly higher than that of the control group $(\mathrm{P}<0.05)$. Cox regression analysis showed that age, Borrmann classification, degree of differentiation, and history of Helicobacter pylori
\end{abstract}

Correspondence to: Dr Jing Wang, Department of Oncology, Xiangyang No. 1 People's Hospital, Hubei University of Medicine, 15 Jiefang Road, Xiangyang, Hubei 441000, P.R. China

E-mail: rvsug863@163.com

${ }^{*}$ Contributed equally

Key words: chemotherapy, interventional therapy, gastric cancer, IL-6, IL-8, IL-10, efficacy infection were independent prognostic factors for patients with gastric cancer. Compared with traditional treatment, interventional therapy can greatly improve the recovery of gastric cancer patients after chemotherapy, reduce the occurrence of complications and inflammation, and improve the survival rate of patients.

\section{Introduction}

As one of the most common gastrointestinal malignancies, gastric cancer is one of the leading causes of cancer deaths worldwide (1). There are over 950,000 new cases and over 720,000 deaths per year in the world (2). Early symptoms of gastric cancer are not visible, and the early diagnosis rate of gastric cancer is generally low. Most patients are diagnosed as advanced gastric cancer at the time of initial clinical visit. Moreover, cancer cells have serious invasion of local target lesions and easily metastasize, so the efficacy is generally poor (3). Data show that the five-year total survival rate of gastric cancer is low (4). According to Japanese guidelines for the treatment of gastric cancer (5), for unresectable advanced gastric cancer and recurrent cancer, chemotherapy is able to achieve great tumor degeneration, but it is still difficult to completely cure. Therefore, it is of vital importance to explore new treatment methods to improve the prognosis of patients with gastric cancer.

Interventional radiology, a method of using catheter and guidewire puncture or directly through human body tube under the guidance of imaging technology to deepen focus on angiography or direct local administration of drugs, has a history of more than 50 years, and due to the minimally invasive execution, as well as the advantages of high safety and good efficacy in angiography, it has been used in angiography, stent transplantation and regional cancer treatment (6). Literature has shown that interventional therapy is a minimally invasive treatment with good efficacy for gastric cancer patients who cannot be treated by surgery and have distant metastasis, which can inhibit tumor development and bring hope to the majority of patients (7). However, interventional therapy cannot fully meet the treatment needs of patients, and there are still some limitations, such as high technical requirements of many specific therapeutic targets for operators, low tumor clearance rate, and easy postoperative recurrence $(8,9)$.

Existing studies have shown that Helicobacter pylori can attack different cell proteins for a long time to affect the 
host's inflammatory response, thus leading to the occurrence of chronic gastritis, peptic ulcer and even gastric cancer (10). At present, the most common cause of gastric cancer is chronic inflammation caused by Helicobacter pylori (11). Cytokines are an important part of tumor-related inflammation. Literature shows that as common inflammatory cytokines, interleukin-6 (IL-6), interleukin-8 (IL-8) and interleukin-10 (IL-10) all play a certain role in promoting the development of gastric cancer (12-14). In addition, a study has shown that these three inflammatory cytokine gene polymorphisms are associated with the occurrence and development of gastric cancer and gastroduodenal diseases related to Helicobacter pylori (15). Various studies have pointed out that the IL-6 is the key protein between inflammation and gastric cancer and other cancers and proinflammatory cytokines associated with gastric cancer state $(16,17)$. The expression of IL-8 and IL-10 in gastric carcinoma is associated with Helicobacter pylori infection and lymph node metastasis (18). Therefore, IL-6, IL-8 and IL-10 were selected for this study. Currently, there are many studies on the stages and prognosis of gastric cancer with IL-6, IL-8 and IL-10, but few on the interventional treatment after chemotherapy.

The present study tested the levels of IL-6, IL- 8 and IL-10 in the serum of patients before and after treatment, to explore the clinical efficacy of interventional therapy after chemotherapy in patients with gastric cancer and the effect of interventional therapy on inflammatory factors in peripheral blood serum of patients, in order to provide clinical reference for the treatment of patients with gastric cancer.

\section{Patients and methods}

Subjects. A retrospective analysis of 429 patients with gastric cancer treated in Xiangyang No. 1 People's Hospital, Hubei University of Medicine (Xiangyang, China) from July 2008 to December 2014 was performed. Among them, 220 patients received interventional therapy after chemotherapy as the experimental group, and 209 patients received chemotherapy alone as the control group. There were 177 males and 43 females in the experimental group, aged 36-77 years, with an median age of (55.32 \pm 15.25$)$ years. The follow-up duration was 3-36 months, with an average follow-up duration of $(24.94 \pm 2.81)$ months. There were 167 males and 42 females in the control group, aged $32-76$ years, with an median age of $(56.75 \pm 14.89)$ years and an average follow-up duration of $(24.82 \pm 3.64)$ months.

Inclusion criteria were: i) Aged 30-80 years; ii) according to the criteria of Eastern Collaborative Oncology Group (ECOG) in the United States (19), the score $\leq 2$; iii) gastric adenocarcinoma was diagnosed by pathological examination, and clinical, imaging and histopathological data were complete. Exclusion criteria were: i) pregnant or lactating women; ii) patients with obvious contraindications in interventional treatment, such as massive ascites, hemogram and abnormal coagulation function; iii) existence of other systemic malignant tumors; iv) patients with diseases that could affect the evaluation of efficacy.

The present study was approved by the Ethics Committee of Xiangyang No. 1 People's Hospital, Hubei University of Medicine. The patients were explained in detail the contents of the experiment. The patients or their guardians agreed and signed a complete informed consent.

\section{Experimental methods}

Experimental reagents and instruments. Oxaliplatin for injection (Chengdu Changqing pharmaceutical Co., Ltd., H20020648); Tetrahydrofolic acid (Xiamen Yanke biotechnology Co., Ltd., YKIR-14390); Drachen capecitabine tablet (Qilu PharmaceuticalCo.,Ltd.,H20133361); Carcinoembryonic antigen (CEA) radioimmunoassay (RIA) kit (Shanghai X-Y Biotechnology Co., Ltd., xy-302); CA-199 Radioimmunoassay kit (Shanghai Xinfan Biotechnology Co., Ltd., XFFMA10-33); IL-6 enzyme-linked immunosorbent assay (ELISA) kit (Shanghai Jingkang Bioengineering Co., Ltd., JKSJ-2176); IL-8 ELISA detection kit (Shanghai YBIO Biotechnology Co., Ltd., IC-IL8-p); IL-10 ELISA detection kit (Shanghai Shock BiologicalCo.,Ltd.,HZ-IL10-Gu); RRIAcounter(Anhui USTC Zonkia Scientific Instruments Co., Ltd., GC-2010); FLUOstar Omega automatic multifunctional microplate reader(Bio-Gene Technology Co., Ltd., FLUOstar Omega); Desktop high-speed centrifuge TG16-WS (Beijing Tiderader Technology Co., Ltd., TG16-WS); Panasonic medical cryogenic refrigerator (Sanyo Corporation, MDF-U5412); Spectrophotometer (Shanghai Genesci Medical Technology Co., Ltd., OD-1000+).

Chemotherapy methods before treatment. The routine chemotherapy regimen used in the experimental and control groups was FOLFOX regimen (20). The specific drugs used were: Oxaliplatin for injection, drug concentration: $135 \mathrm{mg} / \mathrm{m}^{2}$, intravenous drip for $2 \mathrm{~h}, \mathrm{~d} 1$; Tetrahydrofolic acid, drug concentration: $200 \mathrm{mg} / \mathrm{m}^{2}$, intravenous drip for $2 \mathrm{~h}, \mathrm{~d} 1-5$; Capecitabine tablet, drug concentration: $1250 \mathrm{mg} / \mathrm{m}^{2}$, intravenous drip for $2 \mathrm{~h}, \mathrm{~d} 1-5$. The patients underwent the first chemotherapy after the outpatient examination and assessment of their condition. If the patient had no obvious discomfort after chemotherapy, routine chemotherapy was carried out according to this scheme. It was repeated every 4 weeks, 6 times.

Interventional methods. After 6 courses, 3-4 courses of continuous treatment were performed in the patients of the control group. During the process, the treatment was stopped when the patients experienced obvious discomfort. The blood of patients in the control group was collected 3 weeks after treatment.

After 6 courses, patients in the experimental group received interventional surgery. Patients fasted for $>8 \mathrm{~h}$ one night before surgery and were given iodine allergy skin test early in the morning the next day. Atropine $(0.5 \mathrm{mg})$ was injected intramuscularly 30 min before surgery, and $2 \%$ lidocaine was used for local infiltration anesthesia. Femoral artery was successfully punctured by Seldinger technique (21). The hook was set and the metal guidewire were placed on the celiac trunk. The puncture site was pressed adequately, and externally, the power injector was used to perform high pressure angiography at the same time. If the target vessel diameter was too small, and the intubation was difficult, then the microguide wire and microcatheter were used for intubation. According to the different location of the patient's tumor, different parts were selected to perform interventional intubation angiography, and the specific dose was determined by the thickness, blood flow and blood supply of the interventional vessels.

Patients in the experimental group were injected intravenously with antiemetic drugs 15-30 min before experiment, 
and then interventional surgery of arterial infusion chemotherapy was performed. The embolic agent (gelfoam particles) was injected into the target artery for chemoembolization, and hepatic arterial targeted chemoembolization was performed in patients with hepatic metastasis. After embolization, a second angiography was performed to observe the development of the lesion in real time. The surgery was completed when no imaging of the tumor feeding artery was found. In this study, each patient received at least one intervention, with an average of three interventions. After treatment, routine primary nursing care was given after interventional surgery, fasting and water prohibition for $24 \mathrm{~h}$, with bedside electrocardiogram (ECG) monitoring in real time. Patients with liver metastases were treated with liver protection, and postoperative wound bleeding at the femoral artery was closely monitored. The lower limbs were fixed for $8 \mathrm{~h}$ and the patients rested in bed for $24 \mathrm{~h}$. Care workers massaged the lower limbs once every $2 \mathrm{~h}$ to promote blood circulation in the lower extremities and prevent bedsore and thrombosis. At the same time, the control group continued to use conventional chemotherapy, as detailed in 'Experimental reagents and instruments'. Blood samples were taken 3 weeks after treatment.

Collection and treatment of blood samples. From each patient blood was collected twice, two tubes each time, for radioimmunoassay for tumor markers and ELISA method for inflammatory factors, respectively. The samples were collected 2 days before the intervention and 3 weeks after the last intervention in the experimental group, and 2 days before treatment and 3 weeks after the end of the last chemotherapy in the control group. Blood samples were collected and processed as follows: $2 \mathrm{ml}$ elbow vein blood was extracted by vacuum blood sampling needle at a single time from patients after at least $8 \mathrm{~h}$ on an empty stomach and stored in a refrigerator at $4^{\circ} \mathrm{C}$ for $45 \mathrm{~min}$. The condensed blood was then centrifuged at $3,000 \mathrm{x} \mathrm{g}$ at $20^{\circ} \mathrm{C}$ for $15 \mathrm{~min}$. The slurry in test tube was absorbed carefully to obtain the serum which then was stored in a cryogenic refrigerator at $-80^{\circ} \mathrm{C}$.

Laboratory examination of tumor markers in serum. The serum samples were collected from the experimental and control groups, dissolved at room temperature and diluted with $450 \mu \mathrm{l} 0.9 \% \mathrm{NaCl}$ saline. Then $\mathrm{NaHCO}_{3}$ was added to the test tube to adjust $\mathrm{pH}$ to $\sim 7.0$. Finally, $100 \mu \mathrm{l}$ of liquid in test tube was added into CEA and carbohydrate antigen 19-9 (CA19-9) kit, mixed, and placed at $4^{\circ} \mathrm{C}$ overnight. An immune counter was used to measure and count.

Determination of concentrations of $I L-6, I L-8$ and $I L-10$ in serum. The concentrations of IL-6, IL-8 and IL-10 in the collected serum samples were determined by ELISA. Blank control well, sample well and standard well were set first. Sample $(50 \mu \mathrm{l})$ was added to the standard well, and $40 \mu \mathrm{l}$ $0.05 \mathrm{M}$ pH 9.0 buffer solution was dripped into the sample well. Sample $(10 \mu \mathrm{l})$ was added to the sample well and mixed gently. The polystyrene plate was sealed by sealing membrane and placed for $30 \mathrm{~min}$ at $37^{\circ} \mathrm{C}$. The sealing membrane was opened, and the liquid in the reaction well was discarded, then the reaction pore was dried. The well was washed by the washing buffer diluted by distilled water 3 times, 3 min each time. Except the blank well, $50 \mu 1$ enzyme-labeled reagents in the kit was added to each reaction well. Then the chromogenic agents $\mathrm{A}$ and $\mathrm{B}$ were added to the three wells, $50 \mu \mathrm{l}$ each in turn, and the liquid in each well was mixed gently. Reaction stop buffer $(50 \mu \mathrm{l})$ was added to each well to terminate the reaction, and yellow appeared in the reaction well. Within $15 \mathrm{~min}$, the optical density (OD value) of each reaction well was measured by spectrophotometer at the wavelength of $450 \mathrm{~nm}$ with a blank well as a zero setting reference. The standard curve was used to calculate the concentrations of IL-6, IL-8 and IL-10 in serum.

Observation indexes. i) According to the modified Response Evaluation Criteria In Solid Tumors (RECIST) (22), the efficacy of patients can be divided into: Complete remission (CR): All the target lesions have disappeared and the short diameter of all pathological lymph nodes are decreased to $<10 \mathrm{~mm}$; Partial remission (PR): The diameter and baseline level of the target lesion are reduced to $30 \%$; Stability of disease (SD): The condition of target lesion is between PR and progression of disease (PD); PD: In the whole experiment, diameter sums of all target lesions relatively increased at least $20 \%$, and the absolute value of the diameter sums increased at least $5 \mathrm{~mm}$. The disease control rate $(\mathrm{DCR})=(\mathrm{CR}+\mathrm{PR}+\mathrm{SD}) /$ total number of cases $\mathrm{x} 100 \%$. ii) According to Common toxicity criteria (23), the degree of nausea, vomiting and liver and kidney damage caused by the use of drugs in patients with gastric cancer was graded, and the incidence rate of toxic and side effects was compared between the experimental and control groups. iii) Telephone follow-up was conducted once a month to ask patients about their survival.

Statistical analysis. The experimental data were analyzed by SPSS 17.0 software (SPSS Inc.). The figures were made with GraphPadPrism 7 (Beijing Huanzhongruichi Technology Co., Ltd.). The enumeration data were represented by percentage $(\%)$. Chi-square $\left(\chi^{2}\right)$ test was used for comparison between the groups, and partitions of $\chi^{2}$ method was used for pairwise comparison. The measurement data were expressed as (mean $\pm \mathrm{SD}$ ) and were first tested for normality. $\mathrm{t}$-test was used when the data conformed to the normal distribution, and the rank-sum test was used when the data were not in the normal distribution. Pearson's correlation analysis was used to test the correlation between CEA, CA-199 and IL-6, IL-8 and IL-10. Survival analysis was performed using Kaplan-Meier. Log-rank test was used to test, and univariate and multivariate analyses were performed on the prognostic factors of patients using Cox regression model of single factor analysis. At $\mathrm{P}<0.05$, the difference was considered statistically significant.

\section{Results}

General clinical data comparison. As shown in Table I, there was no difference in age, body mass index (BMI) and follow-up duration and other factors between the experimental and control groups $(\mathrm{P}>0.05)$. According to the American Joint Committee on Cancer (AJCC) pathological staging gastric 
Table I. Comparison of general clinical data between the experimental and control groups (mean \pm SD) [n (\%)].

\begin{tabular}{|c|c|c|c|c|}
\hline Clinical factors & $\begin{array}{l}\text { Experimental group } \\
\qquad(n=220)\end{array}$ & $\begin{array}{l}\text { Control group } \\
\quad(n=209)\end{array}$ & $\mathrm{t} / \chi^{2}$ & P-value \\
\hline Follow-up duration (month) & $24.94 \pm 2.81$ & $24.82 \pm 3.64$ & 0.324 & 0.750 \\
\hline BMI $\left(\mathrm{kg} / \mathrm{m}^{2}\right)$ & $24.68 \pm 1.36$ & $24.81 \pm 1.14$ & 1.076 & 0.285 \\
\hline Heart rate (time/minute) & $103.51 \pm 12.36$ & $104.24 \pm 11.54$ & 0.632 & 0.528 \\
\hline Age (years) & & & 0.072 & 0.788 \\
\hline$\leq 50$ & $87(39.55)$ & $80(38.28)$ & & \\
\hline$>50$ & $133(60.45)$ & $129(61.72)$ & & \\
\hline $\operatorname{Sex}[\mathrm{n}(\%)]$ & & & 0.201 & 0.886 \\
\hline Male & $177(80.45)$ & $167(79.90)$ & & \\
\hline Female & $43(19.55)$ & $42(20.10)$ & & \\
\hline Tumor stage & & & 1.525 & 0.217 \\
\hline $\mathrm{I}+\mathrm{II}$ & $109(49.55)$ & $116(55.50)$ & & \\
\hline IIIa+IIIb & $111(50.45)$ & $93(44.50)$ & & \\
\hline Borrmann type & & & 0.001 & 0.972 \\
\hline $\mathrm{I}+\mathrm{II}$ & $54(24.55)$ & $51(24.40)$ & & \\
\hline III+IV & $166(75.45)$ & $158(75.60)$ & & \\
\hline Degree of differentiation & & & 0.207 & 0.901 \\
\hline Differentiated & $35(15.91)$ & $33(15.79)$ & & \\
\hline Poorly differentiated & $106(48.18)$ & $105(50.24)$ & & \\
\hline Undifferentiated & $79(35.91)$ & $71(33.97)$ & & \\
\hline History of Helicobacter pylori infection & & & 0.077 & 0.781 \\
\hline No & $104(47.27)$ & $96(45.93)$ & & \\
\hline Yes & $116(52.73)$ & $113(54.07)$ & & \\
\hline History of peptic ulcer & & & 0.012 & 0.913 \\
\hline No & $102(46.36)$ & $98(46.89)$ & & \\
\hline Yes & $118(53.64)$ & $111(53.11)$ & & \\
\hline Chemotherapy cycle before experiment & & & 0.001 & 0.989 \\
\hline$\leq 4$ & $178(80.91)$ & $169(80.86)$ & & \\
\hline$>4$ & $42(19.09)$ & $40(19.14)$ & & \\
\hline Prophylactic anti-inflammatory therapy & & & 1.780 & 0.182 \\
\hline No & $12(5.45)$ & $6 \quad(2.87)$ & & \\
\hline Yes & $208(94.55)$ & $203(97.13)$ & & \\
\hline Smoking history & & & 0.155 & 0.694 \\
\hline No & $101(45.91)$ & $92(44.02)$ & & \\
\hline Yes & $119(54.09)$ & $117(55.98)$ & & \\
\hline Serum creatinine $[\mathrm{n}(\%)]$ & & & 0.008 & 0.983 \\
\hline$<133 \mu \mathrm{mol} / 1$ & $64(20.09)$ & $61(29.19)$ & & \\
\hline$\geq 133 \mu \mathrm{mol} / 1$ & $156(70.91)$ & $148(70.81)$ & & \\
\hline Blood urea nitrogen [n (\%)] & & & 0.004 & 0.947 \\
\hline$<7.14 \mathrm{mmol} / \mathrm{l}$ & $49(22.27)$ & $46(22.01)$ & & \\
\hline$\geq 7.14 \mathrm{mmol} / \mathrm{l}$ & $171(77.73)$ & 163 (77.99) & & \\
\hline
\end{tabular}

t-test was used to analyze the data of follow-up duration, BMI and heart rate. Chi-square $\left(\chi^{2}\right)$ test was used in the analysis of age, sex, tumor stage, Borrmann type, degree of differentiation, history of Helicobacter pylori infection, history of peptic ulcer, chemotherapy cycle before experiment, prophylactic anti-inflammatory therapy, smoking history, serum creatinine and blood urea nitrogen. BMI, body bass index.

cancer (24), in the experimental group, 109 patients were at stage I+II, and 111 patients were at stage IIIa+IIIb; while in the control group, 116 patients were at stage I+II, and 93 patients were at stage IIIa+IIIb. According to the Borrmann type (25), in the experimental group, 54 patients were at stage I+II, and 166 patients were at stage III+IV; while in the control group, 
Table II. Comparison of tumor markers between the experimental and control groups (mean \pm SD).

\begin{tabular}{|c|c|c|c|c|}
\hline Factors & $\begin{array}{l}\text { Experimental group } \\
\qquad(\mathrm{n}=220)\end{array}$ & $\begin{array}{l}\text { Control group } \\
\qquad(n=209)\end{array}$ & $\mathrm{t}$ & P-value \\
\hline \multicolumn{5}{|l|}{$\mathrm{CEA}(\mu \mathrm{g} / \mathrm{l})$} \\
\hline 2 days before treatment & $5.98 \pm 2.57$ & $6.14 \pm 2.53$ & 0.649 & 0.516 \\
\hline 3 weeks after treatment & $5.42 \pm 2.03^{\mathrm{a}, \mathrm{c}}$ & $6.02 \pm 2.61$ & 2.665 & 0.008 \\
\hline \multicolumn{5}{|l|}{ CA19-9 (U/ml) } \\
\hline 2 days before treatment & $42.35 \pm 1.76$ & $42.15 \pm 1.04$ & 1.424 & 0.155 \\
\hline 3 weeks after treatment & $39.62 \pm 1.37^{\mathrm{b}, \mathrm{d}}$ & $41.97 \pm 1.28$ & 18.332 & $<0.001$ \\
\hline
\end{tabular}

51 patients were at stage $\mathrm{I}+\mathrm{II}$, and 158 patients were at stage III+IV There was no statistical difference between the experimental and control groups in terms of tumor stage, Borrmann type, differentiation degree, history of Helicobacter pylori infection, history of peptic ulcer, and preexperimental treatment $(\mathrm{P}>0.05)$.

Comparison of tumor markers between the experimental and control groups after treatment. The concentrations of CEA in the serum of the experimental and control groups 2 days before treatment were $(5.98 \pm 2.57)$ and $(6.14 \pm 2.53) \mu \mathrm{g} / \mathrm{l}$; The concentrations of CA19-9 in serum of the experimental and control groups 2 days before treatment were $(42.35 \pm 1.76)$ and $(42.15 \pm 1.04) \mathrm{U} / \mathrm{ml}$. The concentrations of CEA in the serum of the experimental and control groups 3 weeks after treatment were $(5.42 \pm 2.03)$ and $(6.02 \pm 2.61) \mu \mathrm{g} / 1$. The concentrations of CEA and CA19-9 in the serum of the experimental and control groups 3 weeks after treatment were $(39.62 \pm 1.37)$ and $(41.97 \pm 1.28) \mathrm{U} / \mathrm{ml}$. There was no significant difference in the concentrations of CEA and CA19-9 between the experimental and control groups before treatment $(\mathrm{P}>0.05)$. The concentrations of CEA and CA19-9 in the experimental group after treatment were lower than that before treatment $(\mathrm{P}<0.05)$, and there was no significant difference in the control group before and after treatment $(\mathrm{P}>0.05)$. The concentrations of CEA and CA19-9 in the experimental group after treatment was lower than that in the control group at the same time $(\mathrm{P}<0.05)$. Specific data are shown in Table II.

Comparison of efficacy between the experimental and control groups. In the experimental group, there were 12 cases of CR, 68 cases of $\mathrm{PR}, 113$ cases of $\mathrm{SD}$, and 27 cases of $\mathrm{PD}$, and the DCR was $87.73 \%(193 / 220)$ after treatment. In the control group, there were 6 cases of CR, 28 cases of PR, 110 cases of SD, and 65 cases of PD, and the DCR was $68.90 \%(144 / 209)$ after treatment. There was no significant difference in CR and SD patients between the experimental and control groups $(\mathrm{P}>0.05)$. There were significantly more PR patients in the experimental group than the control group, and significantly
Table III. Comparison of efficacy between the experimental and control groups [n (\%)].

\begin{tabular}{lcccr}
\hline Items & $\begin{array}{c}\text { Experimental group } \\
(\mathrm{n}=220)\end{array}$ & $\begin{array}{c}\text { Control group } \\
(\mathrm{n}=209)\end{array}$ & $\chi^{2}$ & P-value \\
\hline $\mathrm{CR}$ & $12(5.45)$ & $6(2.87)$ & & \\
$\mathrm{PR}$ & $68(30.91)$ & $28(13.40)$ & & \\
$\mathrm{SD}$ & $113(51.36)$ & $110(52.63)$ & & \\
PD & $27(12.27)$ & $65(31.10)$ & & \\
DCR & 87.73 & 68.90 & 22.552 & $<0.001$
\end{tabular}

The Chi-square $\left(\chi^{2}\right)$ test was used for the comparison of efficacy. $\mathrm{CR}$, complete remission; $\mathrm{PR}$, partial remission; SD, stable disease; $\mathrm{PD}$, disease progression; DCR, disease control rate.

less PD patients in the experimental group than in the control group. The DCR of the experimental group was significantly higher than that of the control group $(\mathrm{P}<0.001)$ (Table III).

Grade of the side effects between the experimental and control groups. According to the Common toxicity criteria, grade III-IV of severe side effects in the experimental group and the control group were compared. The incidence of side effects in the experimental group was significantly lower than that in the control group, $\mathrm{P}<0.05$, which suggested that interventional therapy could alleviate the side effects in patients with gastric cancer. Detailed information is provided in Table IV.

Comparison of serum levels of $I L-6, I L-8$ and $I L-10$ before and after treatment between the experimental and control groups. There was no significant difference in serum IL-6, IL-8 and IL-10 concentrations between the two groups 2 days before treatment $(\mathrm{P}>0.05)$. The serum levels of IL-6, IL-8 and IL-10 in the experimental group were significantly lower than those in the control group 3 weeks after treatment $(\mathrm{P}<0.05)$. The serum levels of IL- 6 , IL- 8 and IL-10 in the experimental 
Table IV. Grade of side effects between the experimental and control groups [n (\%)].

\begin{tabular}{lccrr}
\hline & \multicolumn{3}{c}{ III-IV } \\
\cline { 2 - 5 } Factors & $\begin{array}{c}\text { Experimental group } \\
(\mathrm{n}=220)\end{array}$ & $\begin{array}{c}\text { Control group } \\
(\mathrm{n}=209)\end{array}$ & $\chi^{2}$ & P-value \\
\hline Nausea & $23.18(51 / 220)$ & $40.19(84 / 209)$ & 14.382 & 0.001 \\
Vomiting & $20.45(45 / 220)$ & $37.80(79 / 209)$ & 15.688 & $<0.001$ \\
Hepatic damage & $10.45(23 / 220)$ & $25.84(54 / 209)$ & 17.219 & $<0.001$ \\
Renal damage & $22.27(49 / 220)$ & $31.10(65 / 209)$ & 4.281 & 0.039 \\
\hline
\end{tabular}

The Chi-square $\left(\chi^{2}\right)$ test was used to compare the side effect grades.

Table V. Comparison of relative indicators before and after treatment between the experimental and control groups (mean \pm SD).

\begin{tabular}{|c|c|c|c|c|}
\hline Factors & Before treatment & After treatment & $\mathrm{t}$ & P-value \\
\hline \multicolumn{5}{|l|}{ IL-6 (pg/ml) } \\
\hline Experimental group $(\mathrm{n}=220)$ & $78.34 \pm 25.12$ & $58.23 \pm 15.75^{\mathrm{d}}$ & 9.875 & $<0.001$ \\
\hline Control group $(\mathrm{n}=209)$ & $78.56 \pm 29.45$ & $79.36 \pm 28.34^{\mathrm{a}}$ & 0.775 & 0.286 \\
\hline \multicolumn{5}{|l|}{ IL-8 (pg/ml) } \\
\hline Experimental group $(\mathrm{n}=220)$ & $89.36 \pm 5.36$ & $61.12 \pm 18.42^{\mathrm{e}}$ & 21.793 & $<0.001$ \\
\hline Control group $(\mathrm{n}=209)$ & $89.04 \pm 5.41$ & $89.86 \pm 6.67^{b}$ & 1.402 & 0.162 \\
\hline \multicolumn{5}{|l|}{ IL-10 (pg/ml) } \\
\hline Experimental group (n=220) & $69.57 \pm 5.32$ & $67.26 \pm 5.23^{\mathrm{f}}$ & 30.441 & $<0.001$ \\
\hline Control group (n=209) & $68.65 \pm 5.36$ & $68.37 \pm 5.46^{\mathrm{c}}$ & 0.593 & 0.553 \\
\hline
\end{tabular}

group 3 weeks after treatment were significantly decreased compared with those 2 days before treatment $(\mathrm{P}<0.05)$. Specific data are shown in Table V.

Correlation analysis of tumor markers with $I L-6, I L-8$ and IL-10 concentrations. Pearson's correlation test was used to analyze the correlation between CEA, CA19-9 and IL-6, IL-8 and IL-10 concentrations before and after the experiment. The results showed that the serum CEA concentration of the experimental group was positively correlated with the serum IL-6, IL-8 and IL-10 concentrations of patients before treatment $(\mathrm{r}=0.420,0.397,0.503, \mathrm{P}<0.001)$. Before treatment, the serum CA19-9 concentration of the experimental group was positively correlated with the serum IL- 6 , IL- 8 and IL-10 concentrations $(\mathrm{r}=0.410,0.257,0.468, \mathrm{P}<0.001)$. After treatment, the serum CEA concentration of patients in the experimental group was positively correlated with IL-6, IL-8 and IL-10 concentrations ( $\mathrm{r}=0.417,0.355,0.334, \mathrm{P}<0.001)$. After treatment, the serum CA19-9 concentration of patients in the experimental group was positively correlated with IL-6, IL-8 and IL-10 concentrations $(r=0.324,0.249,0.408$, $\mathrm{P}<0.001)$. After treatment, the correlation between CEA,
CA19-9 and IL-6, IL-8 and IL-10 decreased slightly but not significantly (Fig. 1).

Comparison of survival analysis between the experimental and control groups. The median overall survival (mOS) in the experimental group was 13 months (95\% CI, 1.057-1.598), and the mOS in the control group was 10 months (95\% CI, 0.6256-0.9458). The 3-year overall survival rate in the two groups was 16.36 and $9.09 \%$, respectively. The median survival time and overall survival rate in the experimental group were significantly higher than those in the control group $\left(\chi^{2}=6.440, \mathrm{P}<0.05\right)$, and the difference was statistically significant. The survival curve is shown in Fig. 2. The annual survival rate was obtained by comparing the number of survivors per year with the total number of individuals. The 1-, 2- and 3-year survival rates in the experimental group were higher than those in the control group $(\mathrm{P}<0.05)$ (Table VI and Fig. 2).

Factors affecting postoperative survival of patients after the experimental intervention treatment was analyzed by Cox regression model. The results of single factor analysis showed that age, Borrmann type, differentiation degree and 



Figure 1. Correlation analysis of tumor markers with IL-6, IL-8 and IL-10 concentration before and after the experiment was performed by Pearson's correlation test. Serum CEA concentration of the experimental group before treatment was positively correlated with the serum IL-6, IL- 8 and IL-10 concentrations of the patients $(\mathrm{r}=0.420,0.397,0.503 ; \mathrm{P}<0.001)$. CA19-9 concentration was positively correlated with IL-6, IL- 8 and IL-10 concentrations in patients' serum $(\mathrm{r}=0.410,0.257,0.468 ; \mathrm{P}<0.001)$. After treatment, the serum CEA concentration of the experimental group was positively correlated with the serum IL-6, IL-8 and IL-10 concentrations ( $r=0.417,0.355,0.334 ; \mathrm{P}<0.001)$, and CA19-9 concentration was positively correlated with the serum IL-6, IL-8 and IL-10 concentrations ( $\mathrm{r}=0.324,0.249,0.408 ; \mathrm{P}<0.001)$. (A) Correlation between IL-6 and CEA before treatment. (B) Correlation between IL-8 and CEA before treatment. (C) Correlation between IL-10 and CEA before treatment. (D) Correlation between IL-6 and CEA after treatment. (E) Correlation between IL-8 and CEA after treatment. (F) Correlation between IL-10 and CEA after treatment. (G) Correlation between IL-6 and CA19-9 before treatment. (H) Correlation between IL-8 and CA19-9 before treatment. (I) Correlation between IL-10 and CA19-9 before treatment. (J) Correlation between IL-6 and CA19-9 after treatment. (K) Correlation between IL-8 and CA19-9 after treatment. (L) Correlation between IL-10 and CA19-9 after treatment. 
Table VI. Comparison of survival analysis between the experimental and control groups [n (\%)].

\begin{tabular}{lccccc}
\hline Case/percentage & 1-year & 2-year & 3-year & $\chi^{2}$ & P-value \\
\hline Experimental group $(\mathrm{n}=220)$ & $127(57.73)$ & $78(35.45)^{\mathrm{b}}$ & $36(16.36)^{\mathrm{b}, \mathrm{c}}$ & 81.354 & $<0.001$ \\
Control group $(\mathrm{n}=209)$ & $96(45.93)^{\mathrm{a}}$ & $55(26.32)^{\mathrm{a}, \mathrm{b}}$ & $19(9.09)^{\mathrm{a}-\mathrm{c}}$ & 71.880 & $<0.001$ \\
\hline
\end{tabular}

${ }^{\mathrm{a}} \mathrm{P}<0.05$, compared with the survival rate of the same period in the experimental group. ${ }^{\mathrm{b}} \mathrm{P}<0.05$, compared with the 1 -year survival rate within the group. ${ }^{\mathrm{C}} \mathrm{P}<0.05$, compared with the 2 -year survival rate within the group. The log-rank test was used for the comparison of survival.

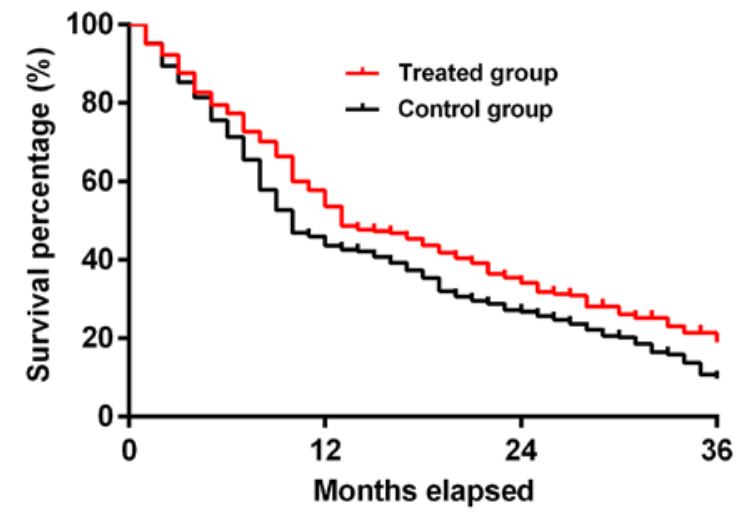

Figure 2. Comparison of the survival time between the experimental and control groups. The results of Kaplan-Meier test showed that the median survival time in the experimental and control groups was 13 months and 10 months, the 3 -year overall survival rate was 16.36 and $9.09 \%$, respectively. The median survival time and overall survival rate in the experimental group were significantly higher than those in the control group $\left(\chi^{2}=6.440, \mathrm{P}<0.05\right)$

the history of Helicobacter pylori infection were associated with the prognosis and survival of patients with gastric cancer treated by interventional therapy $(\mathrm{P}<0.05)$; and sex, tumor stage history of peptic ulcer, experiment before chemotherapy cycle, preventive anti-inflammatory therapy, smoking history, serum creatinine and blood urea nitrogen were not related to the prognosis and survival of patients with gastric cancer treated by interventional therapy $(\mathrm{P}>0.05)$, as shown in Table VII. Multivariate analysis results showed that the age $(\mathrm{P}=0.041)$, Borrmann type $(\mathrm{P}=0.026)$, the degree of differentiation $(\mathrm{P}=0.005)$ and Helicobacter pylori infection $(\mathrm{P}=0.029)$ were associated with the prognosis and survival of patients with gastric cancer treated by interventional therapy. Patients aged $>50$ years, with infiltrating ulcer type or diffuse infiltration type, undifferentiated type, and free of Helicobacter pylori infection had poor prognosis (Table VIII).

\section{Discussion}

In modern society, the aging of population is becoming more obvious. As the incidence of gastric cancer is increasing with age, the number of elderly gastric cancer patients is also increasing. The elderly patients have poor immunity, poor surgical tolerance and difficulty in recovery (26). For patients who cannot tolerate surgery, the most important clinical treatment method is still chemotherapy, but most of the chemotherapy drugs, such as paclitaxel and epirubicin, have relatively obvious toxic side effects, and cannot be used for long time periods (27). Therefore, it is important to search for new and safe treatment methods for the prognosis and survival of gastric cancer patients.

Infusion chemoembolization, a common interventional therapy, takes chemotherapeutic drugs through blood vessels to the tumor, while using gelfoam particles to block tumor blood vessels directly, and at the same time using lipiodol to immerse cancer cells directly in high concentrations of drugs to accurately strike cancer cells, which makes up for the insufficient intensity of local target lesions in systemic intravenous chemotherapy (28). However, there are few studies on interventional therapy for patients with gastric cancer, so we focused on the analysis of the efficacy of interventional therapy for patients with gastric cancer after chemotherapy, in order to provide clinical reference for patients with gastric cancer.

It was found that the serum level of tumor marker CEA and CA19-9 in patients treated with interventional therapy was significantly lower than that in the control group $(\mathrm{P}<0.05)$, indicating that interventional therapy may cause the change of CEA and CA19-9 in patients. Research shows that CEA is the best tumor marker for gastrointestinal malignancies at present, with low cost and high sensitivity. Its diagnostic accuracy of tumor metastasis and recurrence is higher than other serologic biomarkers (29). CA19-9 is also a common tumor marker in the detection of gastric cancer. It has been reported that the detection of CEA and CA19-9 in serum before surgery can more effectively detect the recurrence of gastric cancer (30). In addition, Lee et al (31) found that the level of CEA and CA19-9 in serum could assess the prognosis of patients after chemotherapy, and the decreased concentration of these two tumor markers was related to the improvement of patients' survival rate. Although the study was aimed at cholangiocarcinoma, another malignancy of the digestive tract, it can also support our study that interventional therapy can reduce the serum marker concentration of patient and possibly improve the prognosis of patient.

The results showed that patients treated with interventional therapy had better efficacy, less side effects and longer survival time than patients with systemic chemotherapy only. The effective rate of treatment in the experimental group was $87.73 \%$, the cumulative 1-, 2- and 3-year survival rates were 57.73, 35.45 and $16.36 \%$, respectively, and the median survival time was 13 months. It is believed that the interventional therapy can focus on the lesions and has a better effect on killing cancer tissue, thus achieving a better efficacy. The relative literature showed that compared with peripheral intravenous administration, interventional therapy can better locate the 
Table VII. Univariate analysis of factors influencing postoperative survival of gastric cancer patients.

\begin{tabular}{|c|c|c|c|}
\hline Factors & Cases & Overall survival & P-value \\
\hline Age (years) & & & 0.008 \\
\hline$\leq 50$ & 87 & $15(12.6-17.2)$ & \\
\hline$>50$ & 133 & $10(8.4-11.2)$ & \\
\hline Sex & & & 0.866 \\
\hline Male & 177 & $13(11.3-15.4)$ & \\
\hline Female & 43 & $13(12.4-14.9)$ & \\
\hline Tumor stage & & & 0.452 \\
\hline $\mathrm{I}+\mathrm{II}$ & 109 & $13(11.0-15.0)$ & \\
\hline IIIa+IIIb & 111 & $13(9.7-16.4)$ & \\
\hline Borrmann type & & & $<0.001$ \\
\hline $\mathrm{I}+\mathrm{II}$ & 54 & $17(16.2-17.8)$ & \\
\hline III+IV & 166 & $9(7.7-10.3)$ & \\
\hline Degree of differentiation & & & $<0.001$ \\
\hline Differentiated & 35 & $15(12.6-10.2)$ & \\
\hline Low differentiated & 106 & $8(5.8-10.2)$ & \\
\hline Undifferentiated & 79 & $5(3.9-6.1)$ & \\
\hline History of Helicobacter pylori infection & & & $<0.001$ \\
\hline No & 104 & $16(14.6-18.6)$ & \\
\hline Yes & 116 & $8(5.3-10.7)$ & \\
\hline History of peptic ulcer & & & 0.692 \\
\hline No & 102 & $12(10.3-14.4)$ & \\
\hline Yes & 118 & $13(8.4-15.8)$ & \\
\hline Chemotherapy cycle before experiment & & & 0.111 \\
\hline$\leq 4$ & 178 & $12(10.5-13.5)$ & \\
\hline$>4$ & 42 & $13(9.5-16.4)$ & \\
\hline Prophylactic anti-inflammatory therapy & & & 0.673 \\
\hline Yes & 208 & $13(10.3-14.7)$ & \\
\hline No & 12 & $12(10.2-13.6)$ & \\
\hline Smoking history & & & 0.301 \\
\hline No & 101 & $13(10.6-15.5)$ & \\
\hline Yes & 119 & $13(10.2-14.8)$ & \\
\hline Serum creatinine & & & 0.561 \\
\hline$<133 \mu \mathrm{mol} / 1$ & 64 & $13(9.3-15.1)$ & \\
\hline$\geq 133 \mu \mathrm{mol} / 1$ & 156 & $13(9.7-14.2)$ & \\
\hline Blood urea nitrogen & & & 0.717 \\
\hline$<7.14 \mathrm{mmol} / \mathrm{l}$ & 49 & $13(10.8-14.2)$ & \\
\hline$\geq 7.14 \mathrm{mmol} / \mathrm{l}$ & 171 & $10(7.4-13.6)$ & \\
\hline
\end{tabular}

Table VIII. Multivariate analysis of factors influencing postoperative survival of gastric cancer patients.

\begin{tabular}{|c|c|c|c|c|c|c|}
\hline Factors & Regression coefficient & Standard error & Wald value & HR & $95 \% \mathrm{CI}$ & P-value \\
\hline Age ( $\leq 50$ years, $>50$ years $)$ & 0.064 & 0.032 & 4.159 & 1.067 & $0.003-1.135$ & 0.041 \\
\hline Borrmann type (I+II, III+IV) & 0.294 & 0.132 & 4.951 & 1.342 & $1.036-1.740$ & 0.026 \\
\hline $\begin{array}{l}\text { Degree of differentiation (differentiated, } \\
\text { low differentiated, undifferentiated) }\end{array}$ & 0.466 & 0.165 & 7.926 & 1.593 & $1.152-2.204$ & 0.005 \\
\hline $\begin{array}{l}\text { History of Helicobacter pylori infection } \\
\text { (no, yes) }\end{array}$ & -1.511 & 0.690 & 4.789 & 0.221 & $0.057-0.854$ & 0.029 \\
\hline
\end{tabular}

HR, hazard ratio; CI, confidence interval. 
treatment site to the tumor target lesion, rather than the tumor adjacent tissue, and can guarantee the drug concentration in the target lesion area, therefore inhibiting tumor growth (32). However, for patients with gastric cancer, the most alarming complication is gastrointestinal hemorrhage (33). Research has shown that in the case of malignant tumor hemorrhage the expected survival and quality of life of patients should be considered. Since 1970s, arterial embolization has been used to treat refractory hemorrhage in cancer patients (34). A study has shown that patients with gastric cancer hemorrhage treated by endoscopy are prone to recurrence and re-hemorrhage; at this point, arterial embolization should be considered, which may lead to better efficacy (35).

Univariate and multivariate analyses were performed on Cox regression model of prognostic factors in patients with gastric cancer. It was found that age, Borrmann type, differentiation degree and history of Helicobacter pylori infection were associated with interventional therapy on the prognosis of patients with gastric cancer survival $(\mathrm{P}<0.05)$, and age $(\mathrm{P}=0.041)$, Borrmann type $(\mathrm{P}=0.026)$, the degree of differentiation $(\mathrm{P}=0.005)$ and Helicobacter pylori infection $(\mathrm{P}=0.029)$ are independent prognostic factors for patients with interventional therapy. Patients aged over 50 years, with Borrmann III+IV type and undifferentiated type, and free of Helicobacter pylori infection had poor prognosis. This study indicated that patients with gastric cancer who were not infected with Helicobacter pylori before operation had poor prognosis and lower survival rate than patients with Helicobacter pylori infection. Negative Helicobacter pylori is an independent prognostic factor for poor prognosis $(36,37)$, which are consistent with our results. We believe that the prognosis of patients with Helicobacter pylori infection can improve activation of antitumor immunity. However, a study has pointed out that Helicobacter pylori is one of the main causes of gastric cancer, and positive Helicobacter pylori can be an independent factor for the prognosis and survival of gastric cancer patients (38). The connection may still need further study. In another study the follow-up analysis of 3,966 patients with gastric cancer, showed that Borrmann I-IV survival rate was $68.1,67.5,55.2$ and $31.8 \%$. Borrmann type III+IV patients had higher percentage of serosal invasion, serous diffusion and undifferentiated ratio than Borrmann type I+II tumor patients, and Borrmann type III+IV patients were prone to lymph node involvement (39), showing that Borrmann type is an independent prognostic factor in patients with gastric cancer. Finally, differentiation degree and age have also been found as independent prognostic factors of gastric cancer patients in other studies (40). The prognosis of patients with low differentiation and older age is generally poor. The above support our views that age, Borrmann classification, degree of differentiation, and history of Helicobacter pylori infection were related to the prognosis of patients with interventional gastric cancer, and more attention should be paid to patients with these risk factors in clinical practice.

After intervention, compared with the control group, the levels of IL-6, IL-8 and IL-10 in the experimental group were significantly decreased, indicating that interventional therapy has some anti-inflammatory effects in patients. As an inflammatory medium with many different functions, IL-6 has been shown to be involved in tumor metastasis and local invasion of gastric cancer, which can induce vascular endothelial growth factor and promote the activity of tumors (41). IL-8 is a chemokine produced by various malignant tumor cells, which can play a role in tumor formation and immunity. A study revealed that IL-8 level in patient serum was correlated with tumor load, and the monitoring of the IL- 8 level was of great significance for prognosis (42). IL-10 is considered to be a tolerant cytokine, which can inhibit the production of pro-inflammatory cytokines in medullary cells such as macrophages and the stimulation ability of $\mathrm{T}$ cells. In addition, a study has shown that it has a non-superfluous tolerance effect in intestinal immunity, which may induce the occurrence of rectal inflammation (43). We found a significant reduction in the three factors after interventional therapy, which can also explain that intervention may be able to regulate the body's immune function, thereby causing a better curative effect. However, due to the limitation of the experimental conditions, we did not study how interventional therapy leads to the lower expression of inflammatory markers.

The study results also showed that the expression of tumor markers CEA and CA19-9 and inflammatory factors IL-6, IL-8, IL-10 in both before and after the experiment present a positive correlation $(\mathrm{P}<0.05)$. After treatment, the correlation between CEA and CA19-9 and IL-6, IL-8 and IL-10 declined slightly, but without a statistically significant difference $(\mathrm{P}>0.05)$. There was an association between IL-6, IL-8, IL-10 and the digestive system tumors. This may be related to the inflammatory response during tumorigenesis, or may be the result of some unknown factors. Currently, there are few reports on correlation between these three inflammatory factors and CEA, CA19-9. Our study indicated that there was a positive correlation. It may be a coincidence, but the result is very interesting, and may provide more potential options for serum biological markers. The mechanisms of the two between tumor markers and interleukins can be one of the key research directions in the future.

There are still some limitations in this study. First, the data which were retrospectively obtained were sometimes inevitably interfered by subjective factors. Second, because the general clinical stages of patients were relatively late, the period of drug intervention was not entirely optimal, and the survival feedback received was not fully comprehensive. Third, the time span of this study was long, and there were some inevitable situation such as loss of visits to patients.

Therefore, interventional therapy has a good tolerance and a high effective rate for gastric cancer patients. It can also alleviate the adverse reactions and is worthy of clinical promotion.

\section{Acknowledgements}

Not applicable.

\section{Funding}

No funding was received.

\section{Availability of data and materials}

The datasets used and/or analyzed during the current study are available from the corresponding author on reasonable request. 


\section{Authors' contributions}

PW drafted the manuscript and was responsible for chemotherapy. PW and JW contributed to interventional therapy. Both authors read and approved the final manuscript.

\section{Ethics approval and consent to participate}

The present study was approved by the Ethics Committee of Xiangyang No. 1 People's Hospital, Hubei University of Medicine (Xiangyang, China). Signed informed consents were obtained from the patients or their guardians.

\section{Patient consent for publication}

Not applicable.

\section{Competing interests}

The authors declare that they have no competing interests.

\section{References}

1. Dong X, Wang G, Zhang G, Ni Z, Suo J, Cui J, Cui A, Yang Q, $\mathrm{Xu} \mathrm{Y}$ and $\mathrm{Li} \mathrm{F}$ : The endothelial lipase protein is promising urinary biomarker for diagnosis of gastric cancer. Diagn Pathol 8: $45,2013$.

2. Torre LA, Bray F, Siegel RL, Ferlay J, Lortet-Tieulent J and Jemal A: Global cancer statistics, 2012. CA Cancer J Clin 65: $87-108,2015$.

3. Shen L, Li J, Xu J, Pan H, Dai G, Qin S, Wang L, Wang J, Yang Z, Shu Y, et al: Bevacizumab plus capecitabine and cisplatin in Chinese patients with inoperable locally advanced or metastatic gastric or gastroesophageal junction cancer: Randomized, double-blind, phase III study (AVATAR study). Gastric Cancer 18: 168-176, 2015.

4. Zeng H, Zheng R, Guo Y, Zhang S, Zou X, Wang N, Zhang L, Tang J, Chen J, Wei K, et al: Cancer survival in China, 2003-2005: A population-based study. Int J Cancer 136: 1921-1930, 2015.

5. Japanese Gastric Cancer Association: Japanese gastric cancer treatment guidelines 2014 (ver. 4). Gastric Cancer 20: 1-19, 2017.

6. Baum RA and Baum S: Interventional radiology: A half century of innovation. Radiology 273 (Suppl): S75-S91, 2014.

7. Vogl TJ, Gruber-Rouh T, Eichler K, Nour-Eldin NE, Trojan J, Zangos S and Naguib NN: Repetitive transarterial chemoembolization (TACE) of liver metastases from gastric cancer: Local control and survival results. Eur J Radiol 82: 258-263, 2013.

8. Chehab MA, Brinjikji W, Copelan A and Venkatesan AM: Navigational tools for interventional radiology and interventional oncology applications. Semin Intervent Radiol 32: 416-427, 2015.

9. Lu DSK, Raman SS, Limanond P, Aziz D, Economou J, Busuttil R and Sayre J: Influence of large peritumoral vessels on outcome of radiofrequency ablation of liver tumors. J Vasc Interv Radiol 14: 1267-1274, 2003.

10. Wang F,MengW,Wang B and QiaoL:Helicobacterpylori-induced gastric inflammation and gastric cancer. Cancer Lett 345 196-202, 2014

11. Rugge M, Fassan M and Graham DY: Epidemiology of gastric cancer. In: Gastric Cancer: Principles and Practice. Strong VE (ed). 1st edition. Springer, Cham, Switzerland, pp23-34, 2015.

12. Fu XL, Duan W, Su CY, Mao FY, Lv YP, Teng YS, Yu PW, Zhuang Y and Zhao YL: Interleukin 6 induces M2 macrophage differentiation by STAT3 activation that correlates with gastric cancer progression. Cancer Immunol Immunother 66: 1597-1608, 2017.

13. Li W, Zhou Y, Yang J, Zhang X, Zhang H, Zhang T, Zhao S, Zheng P, Huo J and Wu H: Gastric cancer-derived mesenchyma stem cells prompt gastric cancer progression through secretion of interleukin-8. J Exp Clin Cancer Res 34: 52-52, 2015.

14. Pachnia D, Drop B, Dworzańska A, Kliszczewska E and Polz-Dacewicz M: Transforming growth factor- $\beta$, interleukin-10, and serological markers in EBV-associated gastric carcinoma. Anticancer Res 37: 4853-4858, 2017.
15. Kang JM, Kim N, Lee DH, Park JH, Lee MK, Kim JS, Jung HC and Song IS: The effects of genetic polymorphisms of IL-6, IL-8, and IL-10 on Helicobacter pylori-induced gastroduodenal diseases in Korea. J Clin Gastroenterol 43: 420-428, 2009.

16. Taniguchi K and Karin M: IL-6 and related cytokines as the critical lynchpins between inflammation and cancer. Semin Immunol 26: 54-74, 2014.

17. Huang SP, Wu MS, Shun CT, Wang HP, Lin MT, Kuo ML and Lin JT: Interleukin-6 increases vascular endothelial growth factor and angiogenesis in gastric carcinoma. J Biomed Sci 11: 517-527, 2004

18. Zhang XY, Chan WY, Whitney BM, Fan DM, Chow JH, Liu Y, $\mathrm{Ng}$ EK and Chung SC: Changes of interleukin expression correlate with Helicobacter pylori infection and lymph node metastases in gastric carcinoma. Diagn Mol Pathol 11: 135-139, 2002.

19. Malalasekera A, Tan CSY, Phan V, Yip PY, Vardy J, Clarke S and Kao S: Eastern Cooperative Oncology Group score: Agreement between non-small-cell lung cancer patients and their oncologists and clinical implications. Cancer Treat Commun 5: 17-21, 2016.

20. Vincent MD, Breadner D, Cripps MC, Jonker DJ, Klimo P, Biagi JJ, Lam W, O'Connell A, Whiston F, Stitt L, et al: Phase I/II trial of dose-reduced capecitabine in elderly patients with advanced colorectal cancer. Curr Oncol 24: e261-e268, 2017.

21. Wang J, Shi H, Yang G, Han G, Zhao M, Duan X, Mi L, Han X, Li N, Shi J, et al: Combined intra-arterial and intravenous chemotherapy for unresectable, advanced gastric cancer has an improved curative effect compared with intravenous chemotherapy only. Oncol Lett 15: 5662-5670, 2018

22. Kim HS, Kim JW, Kim JH, Choi DR, Han AR, Kim MJ, Kim BC and Zang DY: Single-lesion measurement per organ for assessing tumor response in advanced gastric cancer. Oncology 88: 69-75, 2015.

23. Trotti A, Byhardt R, Stetz J, Gwede C, Corn B, Fu K, Gunderson L, McCormick B, Morrisintegral M, Rich T, et al: Common toxicity criteria: version 2.0. An improved reference for grading the acute effects of cancer treatment: Impact on radiotherapy. Int J Radiat Oncol Biol Phys 47: 13-47, 2000.

24. Amin MB, Greene FL, Edge SB, Compton CC, Gershenwald JE, Brookland RK, Meyer L, Gress DM, Byrd DR and Winchester DP: The Eighth Edition AJCC Cancer Staging Manual: Continuing to build a bridge from a population-based to a more 'personalized' approach to cancer staging. CA Cancer J Clin 67: 93-99, 2017.

25. Wang L, Wang X, Kou H, He H, Lu M, Zhou L and Yang Y: Comparing single oral contrast-enhanced ultrasonography and double contrast-enhanced ultrasonography in the preoperative Borrmann classification of advanced gastric cancer. Oncotarget 9: 8716-8724, 2017.

26. Liu G, Jian F, Wang X and Chen L: Fast-track surgery protocol in elderly patients undergoing laparoscopic radical gastrectomy for gastric cancer: A randomized controlled trial. Onco Targets Ther 9: 3345-3351, 2016.

27. Shi J, Gao P, Song Y, Chen X, Li Y, Zhang C, Wang H and Wang Z: Efficacy and safety of taxane-based systemic chemotherapy of advanced gastric cancer: A systematic review and meta-analysis. Sci Rep 7: 5319, 2017.

28. de Baere T, Arai Y, Lencioni R, Geschwind JF, Rilling W, Salem R, Matsui $\mathrm{O}$ and Soulen MC: Treatment of liver tumors with lipiodol TACE: Technical recommendations from experts opinion. Cardiovasc Intervent Radiol 39: 334-343, 2016.

29. Acharya A, Markar SR, Matar M, Ni M and Hanna GB: Use of tumor markers in gastrointestinal cancers: Surgeon perceptions and cost-benefit trade-off analysis. Ann Surg Oncol 24: 1165-1173, 2017.

30. Lee EC, Yang JY, Lee KG, Oh SY, Suh YS, Kong SH, Yang HK and Lee HJ: The value of postoperative serum carcinoembryonic antigen and carbohydrate antigen 19-9 levels for the early detection of gastric cancer recurrence after curative resection. J Gastric Cancer 14: 221-228, 2014.

31. Lee DW, Im SA, Kim YJ, Yang Y, Rhee J, Na II, Lee KH, Kim TY, Han SW, Choi IS, et al: CA19-9 or CEA decline after the first cycle of treatment predicts survival in advanced biliary tract cancer patients treated with S-1 and cisplatin chemotherapy. Cancer Res Treat 49: 807-815, 2017.

32. Kanehira Y, Togami K, Tada $\mathrm{H}$ and Chono $\mathrm{S}$ : Tumor distribution and anti-tumor effect of doxorubicin following intrapulmonary administration to mice with metastatic lung tumor. J Drug Deliv Sci Technol 33: 143-148, 2016.

33. Pucheanu $X$ and Beuran M: Bleeding gastric cancer in young and elderly patients. J Med Life 8: 356-360, 2015. 
34. Niekamp A, Sheth RA, Kuban J, Avritscher R and Ganguli S: Palliative embolization for refractory bleeding. Semin Intervent Radiol 34: 387-397, 2017.

35. Kim YI and Choi IJ: Endoscopic management of tumor bleeding from inoperable gastric cancer. Clin Endosc 48: 121-127, 2015

36. Jung DH, Lee YC, Kim JH, Chung H, Park JC, Shin SK, Lee SK, Kim HI, Hyung WJ and Noh SH: Postoperative Helicobacter pylori infection as a prognostic factor for gastric cancer patients after curative resection. Gut Liver 11: 635-641, 2017.

37. Postlewait LM, Squires MH III, Kooby DA, Poultsides GA, WeberSM,BloomstonM,Fields RC,PawlikTM, Votanopoulos KI, Schmidt CR, et al: Preoperative Helicobacter pylori infection is associated with increased survival after resection of gastric adenocarcinoma. Ann Surg Oncol 23: 1225-1233, 2016.

38. Chang WJ, Du Y, Zhao X, Ma LY and Cao GW: Inflammationrelated factors predicting prognosis of gastric cancer. World $\mathrm{J}$ Gastroenterol 20: 4586-4596, 2014

39. Li C, Oh SJ, Kim S, Hyung WJ, Yan M, Zhu ZG and Noh SH: Macroscopic Borrmann type as a simple prognostic indicator in patients with advanced gastric cancer. Oncology 77: 197-204, 2009.
40. Zu H, Wang H, Li C and Xue Y: Clinicopathologic characteristics and prognostic value of various histological types in advanced gastric cancer. Int J Clin Exp Pathol 7: 5692-5700, 2014.

41. Gopinathan G, Milagre C, Pearce OM, Reynolds LE, Hodivala-Dilke K, Leinster DA, Zhong H, Hollingsworth RE, Thompson R, Whiteford JR, et al: Interleukin-6 stimulates defective angiogenesis. Cancer Res 75: 3098-3107, 2015.

42. Sanmamed MF, Carranza-Rua O, Alfaro C, Oñate C, Martín-Algarra S, Perez G, Landazuri SF, Gonzalez A, Gross S, Rodriguez I, et al: Serum interleukin- 8 reflects tumor burden and treatment response across malignancies of multiple tissue origins. Clin Cancer Res 20: 5697-5707, 2014.

43. Geginat J, Larghi P, Paroni M, Nizzoli G, Penatti A, Pagani M, Gagliani N, Meroni P, Abrignani S and Flavell RA: The light and the dark sides of Interleukin-10 in immune-mediated diseases and cancer. Cytokine Growth Factor Rev 30: 87-93, 2016.

(i) () (9) This work is licensed under a Creative Commons Attribution-NonCommercial-NoDerivatives 4.0 International (CC BY-NC-ND 4.0) License. 